\title{
FORMAÇÃO DE PROFESSORES NA PARAHYBA DO NORTE
}

\author{
Rose Mary de Souza Araújo ${ }^{1}$
}

\section{RESUMO}

Este trabalho tem como objetivo dar visibilidade aos saberes prescritos para a formação de professores para o magistério primário na Parahyba do Norte do século XIX. Nesse sentido, toma-se quatro espaços histórico-temporais onde esses saberes foram normatizados pelo poder público: 1884, 1886, 1892 e 1893. O corpo documental utilizado foi composto por: discursos e relatórios elaborados pelos presidentes da província paraibana, os relatórios dos diretores da instrução pública dirigidos aos presidentes provinciais, Leis e Regulamentos da Instrução Pública e a produção jornalística de época em nível local.O estudo está assentado nos referenciais de Thompson (1981), de Goodson (1995) e de Gramsci (1989). A partir da documentação disponibilizada, observa-se que predominaram os saberes de cultura geral, científica e moral no processo de formação dos professores primários na Província da Parahyba do Norte.

Palavras-chave: Programa de ensino; Formação de professores; Parahyba do Norte.

\section{NORTH-PARAHYBA PROVINCEFORMATION OF TEACHERS}

\begin{abstract}
This paper aims to give visibility to knowledge prescribed for teacher training for primary teachingin North-Parahyba Province nineteenth century. In this sense, it becomes four-historical time lines where this knowledge were standardized by the government in the following years: 1884, 1886, 1892 and 1893. The documental body used was composed of: speeches and reports by presidents of the Paraiban Province, as well as public teaching managers' reports, addressed to Provincial presidents, Lawsand Regulations of public teaching, besides local news papers production of that time. The study isseated in reference material produced by Thompson (1981), Goodson (1995) and Gramsci (1989). From the available documentation, it is observed that dominate the knowledge of general, scientific and moral culture in the training of primary teachers processin North-Parahyba Province.
\end{abstract}

Keywords: Educational program; Formation of teachers; Parahyba do Norte. 


\section{Introdução}

A formação de professores nos diversos contextos histórico-sociais tem se constituído em um campo permanente de disputas de concepções, dinâmicas, currículos, intenções, entre outros. No momento atual, o Ministério da Educação traçou novas diretrizes orientadoras para os cursos de formação de professores com vistas a uma possível adequação à base nacional comum curricular da educação básica brasileira.

Essa retomada nos remete aos processos historicamente efetivados na realidade social brasileira em busca de suas permanências e mudanças. A reconstrução das instituições e práticas educativas relativas a formação de professores nos diversos contextos, ainda é um campo fértil para a historiografia da educação brasileira.

Assim, este texto trata de apresentar um estudo acerca dos saberes que foram formalizados para a formação de professores na província da Parahyba do Norte nos anos de 1884, 1886, 1892 e 1893. Em outro momento investigativo, observamos que nos referidos anos foram publicadas legislações criando e reformando o curso de formação de professores proporcionado na Escola Normal e no Externato Normal vislumbrando a melhoria da qualidade dos serviços educacionais relativos à instrução primária local. Não é por demais recordar que neste momento o discurso oficial dominante, era a necessidade de professores com formação pedagógica para que a Província expandisse o ensino primário. O interesse primordial que motivou investigar a formação de professores foi o de buscar as características e intenções impressas nos programas curriculares de cada reforma publicada pelos gestores públicos paraibanos.

Para tanto, o corpo documental utilizado foi composto por: discursos e relatórios elaborados pelos presidentes da província paraibana, relatórios dos diretores da instrução pública dirigidos aos presidentes provinciais locais, as legislações que foram publicadas e as matérias jornalísticas produzidas na Parahyba do Norte. O diálogo com as fontes foi possibilitado através dos referenciais interpretativos elaborados por Thompson (1981) acerca do papel das evidências, dos fatos e dos documentos para a apreensão e compreensão do movimento histórico e, de Goodson (1995), tomamos basicamente o conceito de currículo enquanto construção social em nível da prescrição.

Finalmente, o nosso trabalho está estruturado em conformidade com as normatizações estabelecidas para a formação de professores na Parahyba do Norte na segunda metade do dezenove. No primeiro analisamos os saberes que foram prescritos, na ocasião em que foi criada - 1884 - oficialmente a primeira Escola Normal paraibana como espaço privilegiado para a formação de professores para o exercício do magistério primário. No segundo, aqueles que foram estabelecidos no Regulamento de $\mathrm{N}^{\circ} 33$ publicado em 1886 que transformou a Escola Normal em Externato Normal. O terceiro trata dos saberes que foram normatizados por ocasião da reforma no Externato Normal em 1892 e, por último, aqueles que estabelecidos na regulamentação que recriou a Escola Normal em 1893.

\section{A Escola Normal de 1884 e seus saberes}

Por força da Lei $\mathrm{N}^{\mathrm{o}} 761$ de 1883 que criou a Escola Normal, oficial e solenemente instalada em 07 de abril de 1885, o presidente José Ayres do Nascimento apresentou o Regulamento No 30 em 30 de julho de 1884 (ARAÚJO, 2010). Esse regulamento, além de reorganizar a instrução pública nos diversos níveis de ensino, deu organicidade a Escola Normal, enquanto modelo escolarizado de formação de professores para o ensino primário na Província paraibana. 
O Artigo 91 do mencionado regulamento determinou a implantação de uma escola normal uma para cada sexo, sob funcionamento de graus: $1^{\circ}$ e $2^{\circ}$ graus. A de $1^{\circ}$ grau foi designada primordialmente para preparar os professores primários. Na mesma legislação não encontramos nenhuma alusão, determinação para a de $2^{\circ}$ grau. Apesar de ser uma para cada sexo, foi prescrito o mesmo programa de ensino a ser cumprido no interstício de dois anos, conforme exposto no Quadro 1.

\section{Quadro 1 \\ Programa de Formação de Professores da Escola Normal de $1^{\circ}$ Grau - 1884}

\begin{tabular}{|c|}
\hline $1^{\circ}$ ANO \\
\hline Língua Nacional \\
Geografia \\
Aritmética \\
Ensino Religioso \\
\hline $2^{\circ}$ ANO \\
\hline Pedagogia e metodologia \\
História \\
Geometria elementar \\
Desenho linear \\
Prendas domésticas (para as alunas) \\
\hline Fonte: Quadro organizado pela autora a partir das \\
informações contidas no Regulamento \\
$\mathrm{N}^{\mathbf{o}} 30$ de 30 de Julho de 1884.
\end{tabular}

A partir das reflexões de Goodson (1995) acerca da organização e funcionamento das instituições escolares inglesas, entendemos que tanto o programa de ensino quanto o processo de formação de professores na Escola Normal paraibana, estiveram adaptados à estrutura sócio-política já existente e às exigências legais expressas no Regulamento de 1884. O discurso oficial era o de proporcionar, estabelecer o caráter profissional e científico no processo de formação de professores com vistas a habilitação destes para o exercício do magistério primário, de modo que não onerasse as finanças públicas da província e ao mesmo tempo respondesse aos anseios e interesses dos grupos e lideranças políticos locais.

O Artigo 92 da legislação supracitada trata de apresentar a organização das cadeiras que deveriam preparar, qualificar o professor para as atividades instrucionais nas escolas primárias. Esta qualificação era uma exigência necessária para a expansão e modernização da instrução pública primária. As matérias a seguir, foram distribuídas conforme as cadeiras dispostas no Quadro 1.

Para a cadeira de Língua Nacional foram selecionados os estudos sobre a gramática teórica e prática, noções de literatura e exercício de redação. Esses conhecimentos são pequenos indícios de que se exigiam dos futuros professores o domínio da língua pátria e de questões literárias a serem transmitidos oportunamente aos futuros alunos nas escolas primárias.

Quanto à cadeira de Pedagogia, estava organizada a partir dos seguintes conteúdos: sua história, organização escolar, metodologia. Educação normal, física e intelectual, prática dos métodos do ensino em todo o seu desenvolvimento e legislação do ensino. Tais prescrições indicam a inclusão da formação técnico-pedagógica dos 
normalistas, ratificando, portanto, a preocupação do legislador em fornecer elementos de ordem profissional, especificamente os de racionalidade técnica para o efetivo exercício do magistério daqueles.

A cadeira de geografia objetivava transmitir algumas noções e conceitos básicos a serem dominados pelos futuros professores. Para tanto, incorporava os seguintes conteúdos: noções de cosmografia, geografia geral, geografia e história prática. Enquanto a matemática, inerente do universo científico, englobava conhecimentos relativos a aritmética, a geometria plana, a metrologia (sistema de pesos e medidas) $e$ ao desenho linear.

Para as cadeiras de Religião e de Prendas domésticas, não foi estabelecido conhecimento e/ou atividade específica. Entretanto, considerando os elementos valorativos, ideológicos que contornaram e se firmaram na realidade social de época, podemos inferir que ambas tinham o caráter prático-utilitário no processo de formação docente voltada para a necessidade social do cidadão de fé - o homem novo para uma sociedade nova.

De um lado, o ensino religioso proporcionaria os elementos necessários à formação da conduta moral daquele profissional do ensino. Do outro lado, as Prendas Domésticas, destinadas exclusivamente ao sexo feminino, se configuram em forte indício de distinção de gênero quanto à escolarização e/ou o acesso aos diversos conhecimentos de ordem científica e literária. Assim, as atividades que englobariam essa última disciplina, provavelmente deveriam fortalecer determinados papéis inerentes e impostos ao universo da mulher no contexto histórico em questão, quais sejam: de esposa, de mãe e de dona de casa e/ou senhoras "distintas e prendadas" da sociedade paraibana.

Como podemos ver, os saberes prescritos para a Escola Normal oficializada em 1884 revelam, mesmo sob o apelo à dimensão técnico-pedagógica, que a formação de professores tinha como base fundamental os conhecimentos culturais, científicos e morais. Assim caberia aos futuros professores ter o domínio de tais conhecimentos e atitudes morais para oportunamente transmitir aos alunos nas escolas primárias.

\section{O Externato Normal de 1886 e seus saberes}

Externato Normal substituiu a Escola Normal por força do Regulamento de $\mathrm{N}^{\mathrm{o}}$ 33 do dia 14 de janeiro de $1886^{2}$. Esse modelo de formação docente institucionalizado na gestão de Antonio Herculano Bandeira Filho estava destinado apenas à clientela feminina

As análises de Goodson (1995) apontam para o fato de que os programas de ensino em nível da prescrição são construídos a partir dos condicionantes sociais e políticos que predominam numa determinada conjuntura. Sabemos que, em cada momento histórico-social, os saberes escolares prescritos, traduzem conteúdos que expressam os principais interesses, necessidades e representações ideológicas de cada contexto que, por sua vez, orientam o que deve ser ou não ensinado nas instituições escolares.

Partindo destas considerações, é muito provável que o legislador tenha estabelecido um programa de ensino para a formação dos professores a partir dos elementos e representações impressas na conjuntura social paraibana de época. Assim sendo, o Regulamento de $\mathrm{N}^{\circ} 33$ de 1886 normatizou os conteúdos de ensino que as alunas do Externato Normal deveriam aprender, para no futuro próximo serem transmitidos nas escolas primárias da Parahyba do Norte. O Quadro 2 apresenta os saberes que foram prescritos pelo regulamento supracitado. 


\section{Quadro 2 \\ Programa do ensino do Externato Normal - 1886}

\begin{tabular}{|c|}
\hline $1^{\circ}$ ANO \\
\hline Português \\
\hline Matemática \\
\hline Desenho \\
\hline Música \\
\hline Ginástica \\
\hline Religião \\
\hline Trabalhos de agulha \\
\hline $2^{\circ}$ ANO \\
\hline Português \\
\hline Matemática \\
\hline Geografia \\
\hline Elementos de ciências físicas e naturais \\
\hline Desenho \\
\hline Música \\
\hline Ginástica \\
\hline Trabalhos de agulha \\
\hline $3^{\circ}$ ANO \\
\hline História \\
\hline Plementos de ciências físicas e naturais \\
\hline Prabalhos práticos \\
\hline
\end{tabular}

Fonte: Quadro organizado pela autora a partir das informações contidas no Artigo $2^{\circ}$ do Regulamento de $\mathrm{N}^{\circ} .33$ de 14 de Fevereiro de 1886.

(Jornal da Parahyba, 14/01/1886).

O programa de ensino exposto no Quadro 2 foi organizado para dar suporteao curso normal no espaço de em três anos. Para esse interstício buscou regulamentar o desenvolvimento intelectual, moral e técnico-profissional com a finalidade de instrumentalizar as futuras normalistas para as atividades instrucionais nas escolas públicas primárias paraibanas. Nessa perspectiva, o Artigo $4^{\circ}$ da legislação citada distribuiu, ordenou os conteúdos a serem lecionados em cada disciplina. As evidências expostas a seguir revelam que se primou mais pela formação científica e de cultura geral do que a formação pedagógica, que teoricamente habilitaria para o trabalho docente.

No caso de Português, para os dois primeiros anos do curso, foram determinados os seguintes conteúdos: Gramática-Leitura corrente e expressiva em prosa e verso; Análise sintática e ortografia e Exercícios de redação.

Para Matemática elou Aritmética, estabelecida para o primeiro ano foram prescritos estudos sobre: Numeração - Teoria das 4 operações fundamentais sobre os inteiros e as frações ordinárias e decimais. Teoria das proporções e suas aplicações: regras três, regras de juros, de desconto. Estudo teórico e prático do sistema métrico.

Enquanto para a disciplina de Geometria, determinada para o $2^{\circ}$ ano, foram escolhidos os conteúdos de geometria plana e noções sumárias sobre a geometria no espaço. Quanto à geografia, buscou-se uma feição científica através dos seguintes temas: Estudo do globo, precedido de noções gerais de cosmografia. Indicação das 
terras e dos mares. Continentes. Explicação das cartas geográficas. Descrição sumária de cada uma das partes do mundo. Quanto a cada país apenas: a raça, a língua, a religião, o governo, a população, a capital e cidades principais, os acidentes geográficos mais importantes. Estudo mais desenvolvido da América do Sul. Geografia do Brasil e particularmente da Província de Paraíba. O como ensinar, foi orientado através do uso de mapas confeccionados pelas alunas.

A disciplina Ciências Físicas e Naturais era revestida de grande importância sob a ótica dos liberais republicanos em função do ideário positivista que fundamentava os movimentos e ações dos seus representantes. Quanto aos conteúdos selecionados, se restringiram apenas a alguns rudimentos dos conhecimentos científicos. Em conformidade com o novo Regulamento, para o segundo ano, os assuntos foram: História natural; Divisão dos fenômenos da natureza; Descrição dos corpos inorgânicos; Exposição dos caracteres dos minerais, das plantas, e dos animais; Princípios de sua classificação e Rudimentos da anatomia e fisiologia humanas.

Já para o terceiro e último ano do curso normal, a mencionada disciplina incorporava os conteúdos a seguir: Recapitulação do curso do ano anterior. Noções gerais da física e de química. Explicação dos fenômenos naturais. Lei do movimento. Lei do peso. Atrações moleculares, o calor, a luz, a eletricidade. Princípios gerais da química. Aplicações. Ensino rudimentar. As aplicações serão frequentes e dar-se-á preferência à parte experimental de modo a desenvolver o gosto das alunas pelas grandes descobertas científicas e captar-lhes melhor a atenção (Regulamento de $\mathrm{N}^{\circ} .33$ de 14 de Fevereiro de 1886).

História, disciplina programada apenas para o terceiro ano, tinha como finalidade trabalhar os acontecimentos memoráveis da história da humanidade e as biografias dos grandes homens na perspectiva do desenvolvimento social. Assim foi dividida em três temas principais: Divisão da história; Enumeração dos fatos capitais da história antiga, média, moderna e contemporânea; História do Brasil: planos gerais e fatos capitais.

Os conteúdos que necessariamente deveriam ser trabalhados nas respectivas disciplinas: Religião, Desenho, Ginástica e Trabalhos de Agulha e Prendas Domésticas, não foram estabelecidos. Considerando o contexto de época, possivelmente a disciplina de Religião, deveria conduzir os processos comportamentais necessários à formação da conduta moral das normalistas para mais tarde ser reproduzida no cotidiano das escolas primárias. Enquanto a de Trabalhos de Agulha e Prendas Domésticas reforçaria os papéis impostos à mulher: do lar.

Pedagogia e Trabalhos Práticos foram programados para o terceiro e último ano do curso normal. Para Pedagogia foram estabelecidos os seguintes temas: "noções gerais sobre a ciência da educação e suas idéias capitais, explicação do mecanismo da escola primária e da legislação provincial sobre a instrução primária"(Sic!). A partir do que foi proposto, aventamos possibilidade de estudos acerca das ideias, pensamentos e teorias pedagógicas que vinham transitando nos meios educacionais, entre os intelectuais e do funcionamento passado de instituições escolares, principalmente, às religiosas.

Trabalhos Práticos, por sua vez, consistiam na formação prática das futuras normalistas em escola anexa, com uma carga horária prevista de dez horas semanais. Essa formação prática, de caráter inovador, estava prevista para ser realizada ao longo do curso através das seguintes modalidades: para o primeiro ano, a observação por parte das alunas nas aulas do ensino primário ministradas na escola anexa; para o segundo ano, ficaram estabelecidas aulas práticas semanais, sob inspeção do diretor do Externato Normal, que também exercia a função de professor da disciplina de Pedagogia. 
Refletindo sobre o conjunto de saberes que foram prescritos para o Externato Normal, observamos que persistiram as dimensões tanto cultural quanto moralizante no processo de formação das professoras. O caráter científico ganhou mais força, fazendo jus ao apelo da modernidade e o profissionalizante, que por sua vez muito solicitado pelos gestores públicos locais, foi minimamente estabelecido. Com efeito, entendemos que o conjunto de saberes estabelecidos pelo regulamento de 1886 enfatizou uma formação de caráter científico das professoras para as escolas primárias paraibanas.

\section{O Externato Normal de 1892 e seus saberes}

A junta governativa paraibana de 1892, sob os auspícios dos princípios republicanos, expediu o Decreto de $\mathrm{N}^{\mathrm{o}} 13$ no dia 12 de Fevereiro do mesmo ano, estabelecendo algumas modificações na estrutura pedagógica e administrativa do Externato Normal. Dentre outras determinações, interessa destacar aqui o programa de ensino.

\section{Quadro 3 \\ Programa de ensino do Externato Normal - 1892}

\begin{tabular}{|c|}
\hline PRIMEIRO ANO \\
\hline Portuguez \\
\hline Arithmetica \\
\hline Francez \\
\hline Calligraphia \\
\hline SEGUNDO ANO \\
\hline Portuguez \\
\hline Arithmetica \\
\hline Francez \\
\hline Geographia \\
\hline Geometria \\
\hline TERCEIRO ANO \\
\hline Historia \\
\hline Sciencias Naturaes \\
\hline Desenho \\
\hline Musica \\
\hline QUARTO ANO \\
\hline Pedagogia (teoria e prática) \\
\hline Sciencias Physicas \\
\hline Musica \\
\hline Trabalhos de agulha e prendas domesticas \\
\hline $\begin{array}{l}\text { Fonte: Quadro organizado pela autora a partir das } \\
\text { informações contidas no Decreto No. 13 de 12 de } \\
\text { Fevereiro de 1892. In: Parahyba, 1892, p. 14-15. }\end{array}$ \\
\hline
\end{tabular}

O programa de ensino normatizado no Artigo 2 do referido Decreto - Quadro 3 - mantém semelhança com o que foi apresentado no item anterior. Assim, comparandoos observa-se algumas alterações. Primeira, aumento da duração do curso para quatro anos. Segunda, a inclusão da disciplina de Francês. Essa medida era considerada necessária aos estudos das futuras normalistas, em virtude de que a produção literária de 
época acerca do conhecimento humano e científico estava escrita na língua francesa. A terceira está relacionada com a supressão do ensino de religião, mediante a instauração do Estado do tipo laico, tornou-se dispensável e a última refere-se a supressão da disciplina denominada de Trabalhos Práticos que contava com dez horas semanais para a realização da prática de magistério das futuras normalistas. Essa atividade, ora considerada primordialmente como um campo da prática docente, foi incluída na disciplina de Pedagogia com redução na carga horária. Conforme o Artigo $5^{\circ}$ do Decreto de 1892, estava prevista apenas duas horas semanais ${ }^{3}$ para a realização tanto de estudos teóricos quanto para as atividades práticas inerentes à formação pedagógica para o exercício do magistério.

Quanto aos conteúdos das mencionadas disciplinas, permaneceram os mesmos que foram determinados no Regulamento de $\mathrm{N}^{\mathrm{o}} 33$ de 14 de Fevereiro de 1886 apresentados na seção anterior. Cumpre destacar apenas as matérias que foram organizadas para a nova disciplina de Francês. Conforme o parágrafo 2 do Artigo 2 do Decreto de $\mathrm{N}^{\mathrm{o}} 13$, "Estudo de Francez no $1^{\circ}$. anno comprehenderá grammatica e principios de tradução; no $2^{\circ}$. anno versão e tradução de clássicos".

As informações encontradas, em específico a que se refere a redução da carga horária das últimas disciplinas - Pedagogia e Trabalhos Práticos - apontam para a possibilidade do comprometimento na formação técnico-profissional das futuras professoras. Nos primórdios do regime republicano, a formação de professores no Externato Normal, esteve pautada na cultura geral e no domínio dos saberes científicos que deveriam ser transmitidos posteriormente às crianças nas escolas de ensino primário da Parahyba do Norte. Dessa forma, o preparo e/ou formação de caráter profissional propriamente dita, ancorando-se nos princípios, nos conhecimentos pedagógicos já veiculados no âmbito social, não se constituíram em prioridade no contexto de então.

\section{A Escola Normal de 1893 e seus saberes}

Em 4 de fevereiro de 1893, foi publicado o Decreto de $\mathrm{N}^{\circ} 7$ substituindo o Externato Normal pela Escola Normal para ambos os sexos. Anexo a esta legislação, encontramos um novo regulamento bastante extenso reorganizando a estrutura e funcionamento do curso de formação de professores. Entre outros aspectos, estabeleceu o programa de ensino que deveria subsidiar a formação dos professores para as escolas públicas primárias paraibanas. Neste momento, o curso normal foi estruturado com duração de três anos, conforme apresentado no Quadro 4. 


\section{Quadro 4}

Programa de ensino da Escola Normal - 1893

\begin{tabular}{|c|}
\hline PRIMEIRO ANO \\
\hline Portuguez \\
\hline Caligrafia \\
\hline Arithmetica \\
\hline Geographia \\
\hline Historia \\
\hline Trabalhos de agulha \\
\hline SEGUNDO ANO \\
\hline Portuguez \\
\hline Francez \\
\hline Álgebra elementar \\
\hline Sciencias Physicas e naturaes \\
\hline Geographia \\
\hline Historia \\
\hline Musica e Trabalhos de agulha \\
\hline Desenho \\
\hline TERCEIRO ANO \\
\hline Portuguez \\
\hline Geometria preliminar \\
\hline Francez \\
\hline Sciencias Physicas e naturaes \\
\hline Pedagogia \\
\hline Moral \\
\hline Desenho \\
\hline Musica, Trabalhos de agulha \\
\hline
\end{tabular}

Fonte: Quadro organizado pela autora a partir das informações contidas no Decreto de $\mathrm{N}^{\mathrm{o}} .7$ de 4 de

Fevereiro de 1893. In: Parahyba do Norte, 1893, p. 39 40.

O Artigo $7^{\circ}$ do regulamento anexo ao referido decreto (p. 40-41), tratou de apresentar de forma concisa e genérica, os saberes que os alunos da Escola Normal deveriam dominar, para posterior exercício no magistério público do ensino primário. Distribuída ao longo dos três anos, a formação dos professores foi organizada a partir da seguinte programação:

1. Portuguez - Grammatica, leitura corrente e expressiva em prosa e verso. Analyse syntaxica e orthographica. Exercícios de redacção. Leitura dos clássicos, em prosa e verso. Analyse dos mesmos. Exercicios grammaticais. Recitação. Redação.

2. Calligraphia - Exposição dos preceitos da arte calligraphica. Exercícios.

3. Arithmetica - Estudo theorico e pratico, metrologia.

4. Geographia - Noções geraes de Geographia universal e estudo da Geographia do Brasil. Recapítulação summaria da Geograhia. Estudo desenvolvido da Geographia do Brasil e especialmente do Estado da Parahyba. 
5. Historia - Noções geraes de Historia universal e estudo da Historia do Brasil. Estudo desenvolvido da História do Brasil e especialmente do Estado da Parahyba.

6. Trabalhos de agulha - Crochet, tricot, bordados. Bordados, costuras e cortes.

7. Francez - Grammatica e tradução simples. Traducção em prosa e verso, regras de composição. Exercicios.

8. Desenho - Exercicio de desenho linear. Desenho de ornatos, flores e paysagens.

9. Algebra elementar - Noções preliminares até equações de $2^{\circ}$. Grão exclusive. Exercicios.

10. Sciencias physicas e naturaes - noções gerais. Noções gerais de physica e chimica. Propriedades geraes dos corpos. Noções summarias sobre os principaes aparelhos empregados na physica. Principios gerais da chimica. Applicações.

11. Musica - Musica elementar, solfejos, iniciação da aprendizagem.

12. Geometria - Geometria plana e noções summarias sobre a geometria no espaço.

13. Pedagogia - Pedagogia geral, methodologia e hygiene escolar.

14. Moral - Exposição sumaria da moral.

Considerando a dinâmica social em que se deu a recriação da Escola Normal paraibana, cogitamos que a escolha das disciplinas que compuseram o programa disposto no Quadro 4, tenha sido inspirada nos ideários dominantes na época, a saber: o da ilustração francesa (enciclopedismo) e o do positivismo comteano (cientificismo). Esse último era a orientação filosófica que vinha fundamentando o reordenamento e o ajuste institucional do contexto de então: republicano.

Além do seu caráter enciclopedista e cientificista, no programa de ensino estabelecido pelo regulamento de 1893 nos chamou atenção a inclusão da Moral enquanto disciplina de caráter formador dos futuros professores primários paraibanos. Possivelmente essa tenha sido efetivada objetivando substituir os conteúdos relacionados ao ensino religioso, que, por sua vez, proporcionava a difusão de comportamentos e atitudes morais necessários à consolidação da nova ordem social. Tomando o Artigo $2^{\circ}$ do regulamento em pauta, as disciplinas de Moral e de Pedagogia constituíam-se uma só cadeira com uma organização de conteúdos disposta de forma concisa e ampla, dificultando a nossa análise.

Por ser uma disciplina inserida no âmbito profissional e de fundamentos teóricopráticos para o exercício do magistério primário, consideramos relevante analisar o caso da Pedagogia tomando como ponto de partida o que foi prescrito no parágrafo segundo do Artigo $4^{\circ}$ do Regulamento de $\mathrm{N}^{\circ} 33$ de 1886 . Este estabelecia que $O$ ensino theorico de pedagogia para o $3 .^{\circ}$ anno limitar se-há á noções gerais sobre a sciencia da educação e suas idéias capitais, explicação do mecanismo da escola primária, e da legislação provincial sobre a instrução primária. (Jornal da Parahyba, 14/01/1886).

Portanto, na nova regulamentação, a indicação dos conteúdos de ensino foi essencialmente lacônica, imprecisa quanto à formação pedagógica dos futuros normalistas. O estabelecido foi: "Pedagogia geral, methodologia e hygiene escolar". Em princípio, a primeira sugeriu uma formação docente ancorada nos estudos, nos pensamentos de caráter pedagógico sem dissociar do fazer, da prática do magistério dos futuros professores. A segunda temática, denominada de methodologia, possivelmente tenha dado prioridade a questão da técnica, da prática voltada para aprender a ensinar no cotidiano das escolas primárias. 
Quanto à outra face do processo de formação docente, representada pela disciplina de Moral foi mais ampla ainda, dificultando assim a nossa leitura sobre as possíveis intenções, tendências da sua inclusão no curso normal, a saber: "Exposição sumaria da moral". Portanto, entendemos que a articulação entre as disciplinas de Pedagogia e de Moral era revestida pela dimensão prático-utilitária. Na verdade, era conveniente e necessária para formar o professor dentro do caráter disciplinador imposto pelo regime republicano. O professor teria que ser provido com um arsenal de conhecimento técnico e de conduta moral para melhor conduzir o processo instrucional nas escolas primárias republicanas no sentido de sustentar o regime social em vias de consolidação sob o ideário da ordem e do progresso.

Verificamos que além da inclusão da moral enquanto disciplina, outra novidade que encontramos no curso normal foi a determinação de conteúdos de caráter higienista compondo a disciplina de Pedagogia. Possivelmente a introdução desses conhecimentos esteve associada com o processo de urbanização do espaço geográfico da Parahyba do Norte, que paulatinamente foi-se configurando a partir dos primeiros anos da República.

Assim o reformador, assumiu atitudes iluministas, fazendo da Escola Normal e do seu processo de formação, um instrumento catalisador do processo de civilidade, de ordem e progresso, formando pessoas, professores a partir dos preceitos higiênicos, no sentido de conformação e disciplina dentro da nova dinâmica social. Estas características também foram observadas por Monarcha (1999) ao analisar a escola normal inserida no processo de urbanização da cidade de São Paulo. Para esse autor, a reorganização de um determinado espaço urbano engendra vários aspectos, elementos conectados, dentre vários, a salubridade e/ou a saúde pública, ou seja,

O espaço urbano é pensado como um conjunto formado por partes ligadas entre si e que não podem ser examinadas, unicamente, em suas particularidades. A diferenciação e hierarquização desse espaço promovem a especialização das funções, além de permitir o fluxo e a circulação de pessoas e mercadorias. (p. 64).

Com expressão de síntese provisória, os saberes normatizados sugerem a preocupação dos legisladores em estabelecer os caminhos - a racionalidade técnica - ao lado dos conhecimentos de caráter científico, que os futuros professores necessariamente deveriam utilizar para aprender e transmitir respectivamente, no cotidiano das escolas públicas primárias paraibanas no século XIX. Corroborando as referências de Gramsci (1989) e de Goodson (1995), as evidências apontam que os diversos programas de ensino estabelecidos para a formação dos professores não passaram de uma estratégia para garantir a disciplina e a conformação social dentro do novo regime político: o republicano.

\section{Considerações finais}

Através desse breve inventário nos fragmentos históricos, foi possível perceber que alguns gestores do poder público paraibano, demonstraram interesse em implantar a formação de professores através de um modelo escolarizado que se assemelhasse às escolas normais dos países ditos civilizados. Modelo esse que assegurasse uma maior qualificação docente basicamente por meio de um conjunto de saberes que em princípio conduziria a melhoria na qualidade da instrução primária,a civilidade e ao progresso social da Parahyba do Norte no dezenove. 
A documentação consultada forneceu significativos indícios de que a formação de professores, através dos saberes que foram propostos e prescritos, privilegiaram a formação cultural, científica, moral e um breve cotejamento da racionalidade técnica. Estas dimensões foram encontradas nos programas de ensino que foram normatizados nos quatros momentos analisados: 1884, 1886, 1892 e 1893.

É interessante ressaltar a contradição nesse processo, pois os discursos oficiais apregoavam que os programas de ensino voltados para a formação de professores deveriam estar fundamentados numa racionalidade técnica e científica, preconizada pela chamada "modernidade". Nesse momento da denominada modernidade, a premissa básica era a implantação de uma ordem racional na ciência - de orientação científicacomo forma de desestabilizar o obscurantismo que vinha impregnando as decisões, as ações nos diversos setores da sociedade, em especifica a educação escolar. Assim fica expresso o hiato entre os discursos oficiais e as determinações em nível da prescrição que ainda caracteriza a dinâmica social na contemporaneidade.

\section{Referências}

AGUIAR, Wellington Hermes Vasconcelos de; MELO, José Octávio de Arruda. Uma cidade de quatro séculos (Evolução e Roteiro). João Pessoa: Governo do Estado da Paraíba, 1985.

ALMEIDA, José Ricardo Pires. Instrução pública no Brasil (1500-1889): História e Legislação. 2. ed. Tradução Antonio Chizzotti. São Paulo: EDUC, 2000.

ARAUJO, José Carlos Souza [et al.], (orgs.). As escolas normais no Brasil: do império à república. Campinas, São Paulo: Alínea, 2008, p. 75-90.

ARAÚJO, Rose Mary de Souza. Escola Normal na Parahyba do Norte: movimento e constituição da formação de professores no século XIX. João Pessoa: Tese de Doutorado, Centro de Educação/Universidade Federal da Paraíba, 2010.

BOTO, Carlota. A Escola do homem novo: entre o Iluminismo e a Revolução Francesa. São Paulo: Editora da UNESP, 1996.

GOODSON, Ivor F. Currículo: teoria e história. Tradução AttílioBrunetta. Petrópolis: Vozes, 1995.

GRAMSCI, Antonio. Concepção dialética da história. Tradução de Carlos Nelson Coutinho. Rio de Janeiro: Civilização Brasileira, 1989.

GRAMSCI, Antonio. Os intelectuais e a organização da cultura. Tradução de Carlos Nelson Coutinho. Rio de Janeiro: Civilização Brasileira, 1988.

GURJÃO, Eliete de Queiroz. Morte e vida das oligarquias: Paraíba (1889-1945).João Pessoa: Editora Universitária/UFPB, 1994.

MONARCHA, Carlos. Escola Normal da Praça: o lado noturno das luzes. Campinas, São Paulo: Editora da Unicamp. 1999. 
PINHEIRO, Antonio Carlos F.; CURY, Claudia Engler (Orgs). Leis e Regulamentos da Instrução da Paraíba no Período Imperial. Brasília: INEP, 2004. Disponível em http://www.inep.gov.br/estatisticas/cdeb_2004/PB.pdf. Acesso em 09/04/2007.

SAVIANI, Dermeval. A pedagogia no Brasil: história e teoria. Campinas, SP: Autores Associados, 2008. (Coleção Memória da Educação).

THOMPSON, Edward Palmer. A miséria da teoria ou um planetário de erros: uma crítica ao pensamento de Althusser. Tradução Waltensir Dutra. Rio de Janeiro: Zahar Editores, 1981.

\section{Relatórios, Mensagens, Falas, Discursos Dos Presidentes, Governadores, Diretores E Inspetores Da Instrução Pública Na Província - Estado Da Parahyba.}

PARAHYBA DO NORTE, Província da. Anexo E, Instrucção Pública, - Directoria da Instrucção Pública em 30 de junho de 1884. [Eugenio Toscano de Britto] In: Relatorio com que o exm. sr. dr. José Ayres do Nascimento abrio a Assembléa Legislativa Provincial desta provincia no dia 1 de agosto de 1884 e officio com que passou a administração ao exm. sr. dr. Antonio Sabino do Monte. Parahyba, Typ. Liberal, 1884. Disponível em: http://www.crl.edu/content/brazil/pari.htm. Acesso em 17/04/2015.

PARAHYBA DO NORTE, Província da. Falla com que o exm. sr.dr.Antonio Herculano de Souza Bandeira, presidente da provincia, abrio a primeira sessão da 26.a legislatura da Assembléa Provincial da Parahyba em 1 de agosto de 1886. Parahyba do Norte, Typ. Liberal, 1886. Disponível em: http://www.crl.edu/content/brazil/pari.htm. Acesso em 17/04/2015.

PARAHYBA DO NORTE, Estado da. Mensagem do Governador Álvaro Lopes Machado ao Congresso Constituinte do Estado da Parahyba em 01 de julho de 1892. Parahyba - Typographia e Lithographia a Vapor - Manoel Henriques, 1892. Disponível em: http://www.crl.edu/content/brazil/pari.htm. Acesso em 18/04/2015.

PARAHYBA. Mensagem apresentada a Assembléa Legislativa pelo Major Dr. Álvaro Lopes Machado presidente do Estado da Parahyba por occasião da Abertura da $2^{a}$ sessão da $1^{\text {a }}$ Legislatura em 3 de agosto de 1893. Parahyba - Typographia e Lithographia a Vapor - Manoel Henriques, 1893. Disponível em: http://www.crl.edu/content/brazil/pari.htm. Acesso em 18/04/2015.

\section{Legislação}

Regulamento do Externato Normal de No. 33. Jornal da Parahyba. Anno XXV, Parahyba do Norte, 14 Jan. 1886. Localizado no Instituto Histórico e Geográfico Paraibano - IHGP.

PARAHYBA, Colleção dos Actos dos Poderes Legislativo e Executivo em 1892. Parahyba, Imprensa Official, 1913.

PARAHYBA DO NORTE, Estado da.Colleção das Leis e Decretos de 1893. Parahyba, Typ. eLith. a vapor - Manoel Henriques, Rua Maciel Pinheiro 37, 1893. 


\section{Documentos Manuscritos}

Regulamento da Instrução Pública No. 30 de 30 de julho de 1884. Caixa 65-B, 1883. Arquivo Público Waldemar Bispo Duarte na Fundação Espaço Cultural - FUNESC.

\section{Artigos De Jornais}

Exposição do estado da Instrucção primaria secundaria da Provincia da Parahyba do Norte a presentado ao Congresso de Instrucção. Diário da Parahyba. Parahyba do Norte, 19 fev. 1884.

Parte Official. Jornal da Parahyba. Anno XXV, Parahyba do Norte, 14 Jan. 1886.

Instrucção Publica: Escola Normal III. Estado da Parahyba. Anno IV, No. 44, Parahyba do Norte, 07 mar. 1893.

Instrucção Publica: Escola Normal IV. Estado da Parahyba. Anno IV, N. 46, Parahyba do norte, 09 mar. 1893.

Externato Normal. Estado da Parahyba. Anno IV, N. 50, Parahyba do Norte, 14 mar. 1893.

\footnotetext{
${ }^{1}$ Universidade Federal da Paraíba.

${ }^{2}$ Regulamento publicado na íntegra pelo Jornal da Parahybado dia 14/01/1886. Jornal encontrado no Instituto Histórico e Geográfico Paraibano - IHGP.

${ }^{3}$ Cumpre ressaltar que a determinação de duas horas semanais era extensiva as disciplinas constitutivas do programa de ensino estabelecido.
}

Recebido: Março/2016.

Aprovado: Março/2017. 